\title{
Comparative Analysis with a Central Case Study and Multiple Reference Case Studies: A Methodological Variant for Policy Analysis in Developing a National Space Policy
}

\author{
Sanath Panawennage ${ }^{1}$, R.L.S. Fernando ${ }^{2}$, Weng Jingnong ${ }^{3}$ \\ ${ }^{I}$ Arthur C Clarke Institute for Modern Technologies, Sri Lanka \\ ${ }^{2}$ University of Sri Jayewardenepura, Sri Lanka \\ ${ }^{3}$ Beihang University, China
}

\begin{abstract}
The present paper advances an innovative methodological variant of the general research approach of 'qualitative comparative analysis among multiple case studies', as an effective approach for policy analysis. This variant is presented as a particularly effective approach in situations that require development, and institution, of the public policy of a country pertaining to a highly specialized subject area that intrinsically stands to benefit from relevant policies and practices of other countries; and it is explicated in the present paper using the process of developing a national space policy for Sri Lanka as the sample instance of policy analysis. The key methodological innovation advanced here involves positioning that country in respect of which the process of development of a new national policy is intended to be informed by way of comparative policy analysis, as the 'central case study', in relation to the other multiple case studies, the latter being primarily chosen for the purpose of enabling, and informing, the cross-case comparative analysis and, hence, positioned, and referred to, as the 'multiple reference-case-studies'. Thus, Sri Lanka, was positioned as the 'central case study', and three other Asian countries, namely India, Thailand and the Philippines, were selected and positioned as the 'reference-case-studies'. This variant provides an effective methodological framework for developing the national space policies of developing countries - a contemporary need of many a developing country making its entry into the space domain.
\end{abstract}

Key words-national space policy, comparative policy analysis, intrinsic policy drivers, central case study, reference case studies, case-oriented comparative analysis

\section{INTRODUCTION}

$\mathrm{P}$ olicy research stands out as a discipline of research that lends itself for analysis using a diverse and extensive variety of methodological approaches, depending on the field, focus and scope of the study as well as the nature of the central research question. While research approaches based on comparative analysis constitutes an important segment of that diverse range of methodological approaches, case-oriented qualitative comparative analysis in turn represents a substantial share of the research approaches in comparative policy analysis - in other words qualitative comparative analysis among multiple case studies stands as an important choice amongst the general methodological approaches available to the policy researcher. The present paper advances an innovative methodological variant from the general research approach of 'qualitative comparative analysis among multiple case studies' as an effective approach for policy analysis. This innovative variant is presented as a particularly useful approach in situations that require development, and institution, of the public policy of a country pertaining to a highly specialized subject area that intrinsically stands to benefit from relevant policies and practices of other countries; and it is explicated using the process of developing a national space policy for Sri Lanka as the sample instance of policy analysis.

The key element of the methodological innovation discussed and introduced in the present paper involves positioning, and referring to, the country that the central research question appertains to-i.e. the country in respect of which the policy imperatives are intended to be newly identified and a new policy developed - as the 'central case study' in relation to other multiple case studies, the latter being primarily chosen for the purpose of enabling, and informing, the cross-case comparative analysis and, hence, positioned, and referred to, as the 'multiple reference-case-studies'.

The present paper aims to systematically describe and establish the efficacy of this variant approach based on a caseoriented qualitative comparative policy analysis study, which is designed for identifying the policy imperatives, in terms of directional and strategic policy elements, that would constitute the national space policy of Sri Lanka - a developing country that has just made its entry into the space domain. Thus, the present context of acquisition, development and application of space technologies in Sri Lanka, which is currently at an early stage in this process, was selected and positioned as the 'central case study', as per the methodological variant being advanced; and the space policy environments of three other Asian countries, namely India, Thailand and the Philippines, which represent three largely different levels of advancement and maturity in their respective national capabilities in space 
technologies and applications, were selected and positioned as the 'reference-case-studies' that enable and inform the process of cross-case comparative analysis with Sri Lanka as the central case study.

The objective of the study is to describe and establish 'qualitative comparative analysis with a central case study and multiple reference case studies' as an effective methodological variant of comparative policy analysis in developing a national space policy.

The research design and methodology primarily involved the following:

i. developing the multiple reference case studies and the central case study, centered on the space policy environments of the respective four countries;

ii. 'within-case analysis' of the three reference case studies to identify the intrinsic policy-drivers, the key elements of directional and strategic policy, and the contextual factors influencing policy, and

iii. 'Cross-case analysis' to identify policy imperatives relevant to the central case study.

The significance of the study is three-fold, and they are stated below in the increasing order of generality. Firstly, and specifically, it provides an effective approach for developing the national space policy of the country selected as the central case study, namely Sri Lanka, and identifies the policy imperatives as regards the directional and strategic policy. Secondly, it provides an effective methodological framework for developing the national space policies of developing countries - a contemporary need of many a developing country making its entry into the space domain and seeking to leverage the applications of satellite communication, spaceborne remote sensing and geographic information systems, and global navigation satellite systems in the country's efforts of sustainable development. Thirdly, it provides an innovative variant to the general theoretical framework of 'qualitative comparative analysis amongst multiple case studies', the use of which may be extended to policy analysis involving the development of public policy in many a distinctly identifiable specific area of public policy, in developing countries, where they stand to benefit from the experience of other countries through comparative policy analysis in relation to them.

\section{LITERATURE REVIEW}

\section{A. Policy Research}

One of the defining characteristics of policy research is obviously the variety and diversity of the approaches available for the research process. The degree of diversity found in the approaches of policy research is underscored by Majchrzak when she chooses to sum up her argument on the diverse and varying, nevertheless valid and effective, approaches available for policy research, with the following quote from Wildavsky (1979, cited in Majchrzak 2011, p. 2), who suggests that 'there can no more be only one approved mode of policy research than there can be only one way of learning' [1].

\section{B. Levels of Policy}

A research inquiry in public policy that involves policy analysis - be it conducted for formulating a new policy, designing an implementation strategy or as part of a policy redesign - needs to identify the 'level of policy', in terms of the three broad levels of policy- namely directional policy, strategic policy or operational policy. Directional policy, which is the most general level of policy making involves indicating the direction and priorities, and the long-term commitment of the organizational entity with regard to key issues or problems that the policy is intended to address; strategic policy indicates the strategic actions to be adopted in pursuing the directional policy; operational policy spells out the details of processes and procedures to guide the day to day operations in implementing the strategic actions [2].

\section{Comparative Analysis as a Research Approach in Public Policy}

Comparative analysis - and its multiple case study-based variant in particular - has evidently got established as a major qualitative research approach in public policy at least over the past three decades. There exists quite a number of varying definitions and interpretations of this research approach, the most explicit roots of which are found for the most part in political science-particularly in the area of comparative politics involving the study of democratic systems, revolutions, welfare States etc. during 1960s and 70s. Some varying perspectives of this vital research approach as viewed by different authors are discussed below.

The fundamental tool of comparative analysis used across all of its varying research designs and methodologies is the principle of comparison-carried out across the multiple entities being studied for evidence of similarities and differences among them. The similarities and differences thus observed lead in the end to rich multidimensional analyses and explanations of the entities or to generalization of some phenomena.

Comparative analysis according to Porta [3] employs three research methods: the experimental method, the statistical method and the comparative method. The term 'comparative method' has sometimes been used by certain authors to refer to all of the above three methods of comparative analysis. Lijphart [4] has positioned the comparative method in relation to three other research methods, namely the experimental method, the statistical method and the case study method, assessing them in terms of their efficacy in the testing of theory through adjudicating among rival explanations and the degree of difficulty to acquire data to employ each method. Thus, of the comparative method, he has commented that 'intensive comparative analysis of a few cases maybe more promising than the more superficial statistical analysis of many cases' [4]. Porta [3] observed that "[t]he comparative method supplements with logical reasoning the lack of a sufficient number of cases for systematic tests via partial correlations. 


\section{Qualitative Comparative Analysis (QCA)}

Comparative analysis in general employs the comparison among "small N" number of cases and its analysis maybe variable-oriented or case-oriented. Qualitative comparative analysis represents the case-oriented approach. According to [5], epistemologically, qualitative comparative analysis (QCA) as a method of scientific inquiry is based on the foundations of the 'method of agreement' and the "method of differences' advanced by JS Mill's (1967 [1843]) “cannons".

As for the disciplines of application of QCA, initially, in late 1980 s and early 1990s it was mostly developed for applications in political science such as comparative politics and applications in historical sociology such as welfare state studies [5]. In the meantime, this research approach in the discipline of public administration was advanced by Agranoff and Radin [6] in 1991 in their paper titled 'comparative case study approach in public administration'-which essentially resembles all the characteristics of qualitative comparative analysis.

Moreover, the extensive use of this approach of inquiry in policy research is evident from the emergence of 'comparative policy analysis' as a separate research approach in public policy. Comparative policy analysis signifies application in the domain of policy research the general research approach of comparative analysis - more specifically its case-oriented qualitative variant QCA.

Further, the emergence of such dedicated academic journals as the 'Journal of Comparative Policy Analysis', which, according to the authors, is dedicated to 'foster theorybuilding and theory-testing from a comparative perspective', because it 'is important intellectually and practically as a means of learning about and improving public policy', clearly indicate the position of prominence that 'Comparative Policy Analysis' has evolved to assume as a dominant research approach in public policy.

\section{E. Policy Research as a Discipline that Naturally Lends itself for Methodological Innovation}

Policy research can be identified as a discipline that naturally lends for methodological innovation, and calls for such innovation, for enhanced effectiveness of the outcomes of research; and this very purpose that the methodological innovation proposed in the present paper is intended to serve. The three references, quoted below, to literature on qualitative research methods in general, and to policy research in particular, stand in evidence of the above proposition.

The first is the comment made in relation to the specific domain of policy research itself, by Wildavsky: 'there can no more be only one approved mode of policy research than there can be only one way of learning' [1], as already referred to, which clearly indicates the scope for methodological innovations.

Secondly, in many contexts, policy research, as well as many other types of qualitative research design, is conducted based on 'pragmatism' as the interpretative framework of the researchers. Creswell provides a synopsis of interpretations to pragmatism advanced by several leading authors:

There are many forms of pragmatism. Individuals holding an interpretive framework based on pragmatism focus on the outcomes of the research - the actions, situations, and consequences of inquiry - rather than antecedent conditions (as in postpositivism). There is a concern with applications"what works" - and solutions to problems (Patton, 1990) [7].

This overwhelmingly justifies the methodological innovation advanced in the present paper, which involves positioning, and referring to, the country that the central research question appertains to-i.e. the country in respect of which the policy imperatives are intended to be newly identified and a new policy developed - as the 'central case study' in relation to the other multiple case studies, which are primarily chosen to serve the function of informing the process of cross-case analysis amongst multiple case studies and, hence, positioned, and referred to, as the 'multiple reference-case-studies'. This is because 'what works' for the country of central-case study that seeks to develop its national policy for the first time in a highly specialized domain of activity such as space technology and applications, would certainly involve the policy imperatives drawn on the basis of a cross-case analysis with the other countries chosen as reference-case-studies, viewed in relation to the context of the central case.

\section{F. Publicly Declared National Space Policies and the Implicit Policies of National Space Establishments}

An important observation pertinent in the present study is that there exists no formally adopted and publicly declared national space policy in the form of a comprehensive public policy document in two of the countries chosen as referencecase-studies, namely India and Thailand. The national space policy of India, for practical purposes, may be considered to be comprised, for the most part, of the implicit policy of India's national space establishment as reflected by its key decisions and actions. There are, nevertheless, two standalone components of publicly declared policy primarily designed to address some specific issues related to space, namely the Frame-work for Satellite Communication Policy in India, approved by the Government in 1997 [8] and the National Remote Sensing Data Policy of 2011 [9]. According to the Department of Space, the government is currently in the final stages of the process of introducing a national space activities act, and also working towards introducing a comprehensive national space policy. The Thai national space policy, on the other hand, may be considered to be comprised in its entirety of the implicit policy of the Thai government and its space establishment, as reflected by its key decisions and actionsimportantly, including the Thai National Space Strategy (2017-2036) - pertaining to Thailand's national space activities [10]. The Philippines, however, has a publicly declared national space policy, which is contained as an integral part of the Philippines' national legislation on space - Philippine Space Act, enacted in 2019 [11]. 


\section{METHODOLOGY}

The general objective of the present policy research inquiry was to describe and establish 'qualitative comparative analysis with a central case study and multiple reference case studies' as an effective methodological variant of comparative policy analysis in developing a national space policy. Given the above general objective, the research design and methodology that was briefly outlined in the introduction of the present paper is further elaborated below, flowing from development of multiple reference case studies and the central case study; through within-case analysis' of the three reference case studies to identify the substantive policy-drivers, elements of directional and strategic policy, and the contextual factors influencing policy; to 'cross-case analysis' aimed at identifying the policy imperatives relevant to the central case study.

The central case studies as well as the three reference case studies were formulated so as to reflect the current overall context of space activities, and the policy environment, in the respective countries based on the following themes:

a. historical evolution of space activities of the country to reach the current status

b. current national capacity in terms of technology and infrastructure

c. extent of current applications

d. human resource capacity building

e. international cooperation

f. institutional structures and mechanisms, and

g. policy, strategy and legislation

Data gathering was mainly carried out by document review, referring to the websites of respective national space agencies and other relevant national institutions of the respective agencies. Data gathering also involved conducting one-to-one teleconferences with a total of five high level officials (including two ex-officials) and experts attached to the said agencies of the respective countries, mainly for the purpose of obtaining further information and clarifications regarding the data gathered from websites and other documents. Thus, those interviews also served the purpose of validating of data. In addition, in respect of the country of central case study, Sri Lanka, the personal experience and knowledge of the first (principal) author of the present paper, having initiated and led in his official capacity the planning and implementation of the country's programme for acquisition and development of national capacity in space technologies, was judiciously brought in mainly in formulating the central case study.

The question of how the present context of development of national capacity in space technology and its applications in the country of central case study is situated in relation to the nexus between the development of national space technology capabilities and evolution of national space policies of other countries constituted an important part of the analysis. This calls for comparative analysis; more specifically a research approach of qualitative comparative analysis amongst multiple case-studies - which, as described in the literature review, represents an approach of inquiry widely used in policy research, and hence the choice of which as the general approach of inquiry in the present study is clearly justified.

Nevertheless, within the above generally established approach of policy analysis, the present study endeavours to introduce and establish an innovative methodological variant of the above approach, fundamentally based on the premise that the object of comparative analysis undertaken here, namely identification of policy imperatives for developing a national space policy, appertains to one amongst the multiple case studies, whilst the other case-studies serve to inform the process of comparative analysis towards the above end.

\section{A. Analytical Framework}

The overall Analytical Framework employed by the innovative methodological variant being introduced in the present study is graphically illustrated in the figure 1 below.

\section{B. Within-case Analysis}

Within-case analysis involved an analysis of the factors that have influenced the national space policies-including implicit policy as reflected by the major decisions and actions of the respective national space establishments, as well as formally adopted and publicly declared policy-of the countries of reference-case-study being studied, in their evolution to the present status, thus leading to identification of the directional and strategic elements of those policies. The factors that have influenced the policy, were identified, in the present study, in two broad categories, as

i. intrinsic policy-drivers, and

ii. contextual factors

1) Intrinsic Policy Drivers: Regardless of whether the national space policy remains, in large part, as formally adopted and publicly declared policy, or as implicit policy reflected by the major decisions and actions of the national space establishment, the intrinsic determinants of national space policy-which have been identified as intrinsic policy-drivers in the present paper-were observed to emanate from a common base of fundamental national interests that are normally relevant to all countries. Those national interests may be identified, albeit with significant interdependencies among them, as,
a. Technological Advancement
b. National Security
c. Sustainable Development
d. Scientific Advancement
e. International Relations 
Figure 1: Analytical Framework

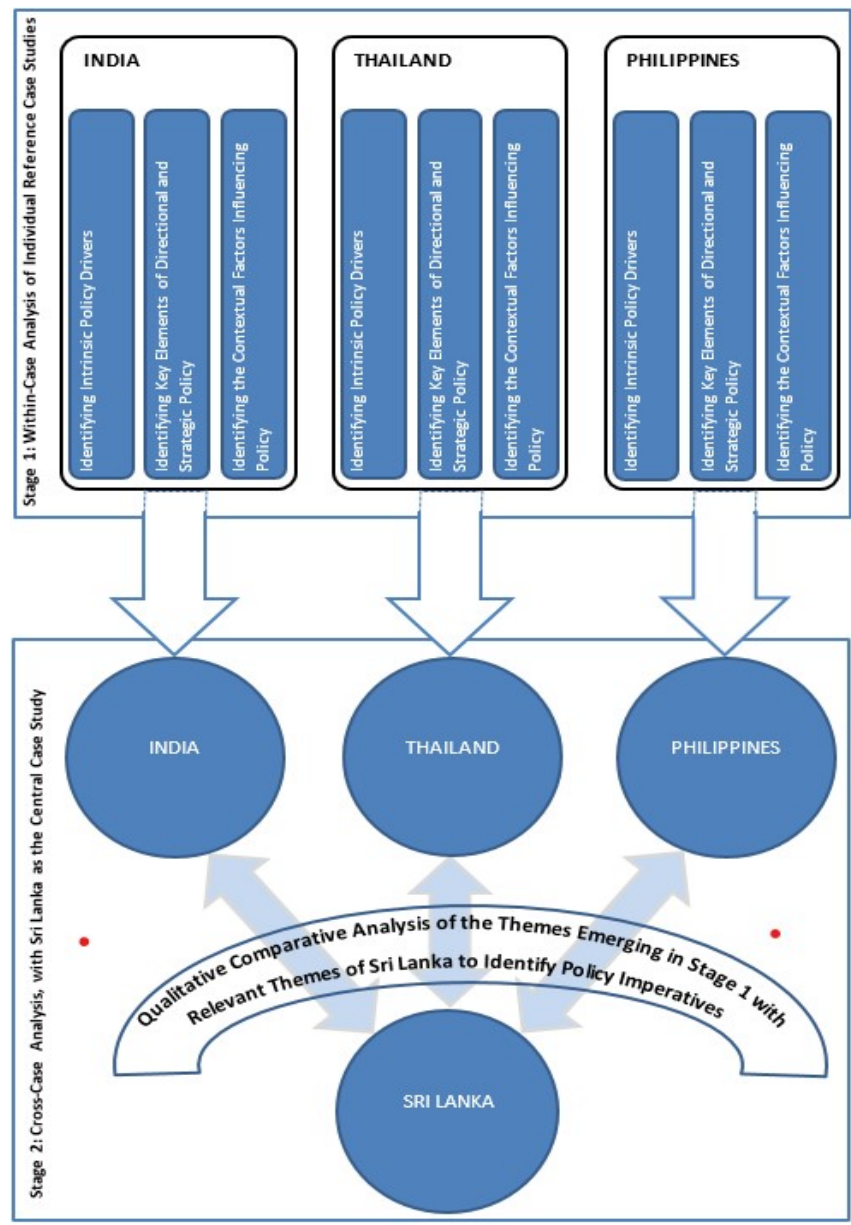

Each of those areas of broader national interest may manifest in the form of one or more of the intrinsic policy-drivers, as identified in the table 1 below, the relative significance of each in terms of its influence in shaping the policy being determined by the country circumstances-ie contextual factors. To foreshadow here, as an example, a fact discussed under 'Section IV-Analysis and Discussion', whereas all of those intrinsic policy-drivers identified therein under the broader national interest 'technological advancement' may be relevant and significant for a leading spacefaring nation such as India, for a new entrant to the space domain, in contrast, where 'the extent of national capabilities in space technologies and applications already acquired or developed by the country' is at a much lower level, what is reasonably significant amongst that list may be limited to those identified as TA2, TA3, TA5 and TA6 in table 1.

2) Contextual factors: It was found that, besides the intrinsic policy-drivers, there are contextual factors that influence the policy in two ways: firstly by way of determining the degree of relevance and significance of each intrinsic policy-driver as a substantive determinant of national space policy, and secondly by way of influencing certain aspects of directional and strategic policy - such as those pertaining to institutional structures of the respective national space establishments- largely in their own right. It was found that the contextual factors mainly comprise the following:

a. extent of national capabilities in space technologies and applications already acquired or developed by the country

b. institutional structure, mechanisms, and decisionmaking practices of the national space establishment (this could be a product, as well as a contextual determinant, of policy)

c. general socio-economic, environmental, political, and technological priorities of the country, and

d. policy directions adopted by the international space community

\section{Cross-case Analysis}

Having analysed, during within-case analysis, the intrinsic policy drivers and the contextual factors that have influenced the national space policy, and having identified the directional and strategic elements of policy, as well as how such policies have been shaped by those intrinsic policy drivers and contextual factors at each distinct phase of evolution of the national space activates in each of the three countries of reference-case-study, the cross-case analysis carried out at the next stage, positioning Sri Lanka as the central case study and other three countries as the reference-case studies, involved comparative analysis of the four cases on the basis of those relationships emerged during within-case analysis,

Cross-case analysis began with an analysis of the significance and relevance of the intrinsic policy drivers in respect of each of the four case-studies. This was followed by identification of directional and strategic policy elements that would potentially represent, and constitute, the policy imperatives in developing a national space policy for Sri Lanka.

The contextual factors, pertaining to the reference-casestudies as well as those pertaining to the central case study Sri Lanka, played a key role in this analysis. This is due to the fact that they help in weighing the relative significance of those intrinsic policy-drivers, as well as the directional and strategic elements of policy, as they apply to the central casestudy, by way of de-contextualizing them initially from their original contexts in the respective countries of reference-casestudy, and then subsequently positioning them against the backdrop of the relevant contextual factors pertaining to Sri Lanka, thereby enabling objective assessment of their relevance and significance in relation to the central case study, Sri Lanka

Table 1: Intrinsic Policy Driver

\begin{tabular}{|l|l|}
\hline $\begin{array}{l}\text { Area of national } \\
\text { interest with respect to } \\
\text { Space }\end{array}$ & Intrinsic policy-drivers \\
\hline $\begin{array}{l}\text { Technological } \\
\text { Advancement (TA) }\end{array}$ & $\bullet \begin{array}{l}\text { National pride: achievement of the } \\
\text { status of a space-capable or space- } \\
\text { faring nation (TA1) }\end{array}$ \\
\hline
\end{tabular}




\begin{tabular}{|c|c|}
\hline & $\begin{array}{l}\text { - Enhanced national capacity for } \\
\text { technological innovation (TA2) } \\
\text { - Technology trickle-down effect: } \\
\text { enhancement of the overall national } \\
\text { base of advanced technological } \\
\text { capabilities (TA3) } \\
\text { Development of commercial space } \\
\text { industry based on core technology } \\
\text { capabilities and services [eg. } \\
\text { manufacturing advanced spacecraft } \\
\text { and launch vehicles, and operating } \\
\text { launch services] (TA4) } \\
\text { Development of commercial space } \\
\text { industry based on manufacturing of } \\
\text { components and intermediate } \\
\text { products, and providing services, in } \\
\text { the upstream value chain activities } \\
\text { (TA5) } \\
\text { Development of commercial space } \\
\text { industry based on predominantly IT- } \\
\text { based and other knowledge-intensive } \\
\text { services in the downstream value } \\
\text { chain (TA6) } \\
\text { Development of intrinsically space- } \\
\text { enabled industries and services [eg. } \\
\text { telecommunication services and } \\
\text { direct-to-home satellite television] } \\
\text { (TA7) }\end{array}$ \\
\hline National Security (NS) & 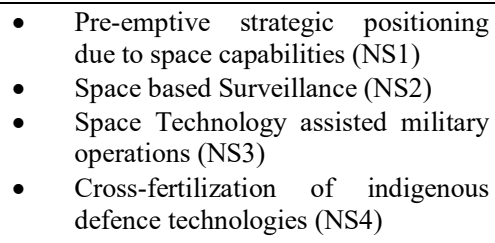 \\
\hline $\begin{array}{l}\text { Sustainable } \\
\text { Development (SD) }\end{array}$ & 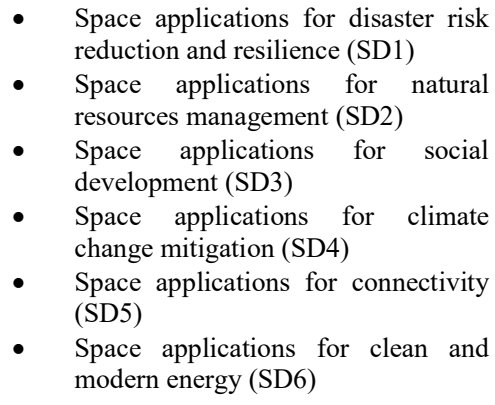 \\
\hline $\begin{array}{l}\text { Scientific } \\
\text { Advancement (SA) }\end{array}$ & $\begin{array}{ll} & \text { Creation of new scientific } \\
\text { knowledge on space (SA1) } \\
\text { - } \quad \begin{array}{l}\text { Space exploration (SA2) } \\
\text { - }\end{array} \\
\begin{array}{l}\text { Promoting science education and } \\
\text { scientific literacy (SA3) }\end{array}\end{array}$ \\
\hline $\begin{array}{l}\text { International Relations } \\
\text { (IR) }\end{array}$ & $\begin{array}{l}\text { - Comparative advantage in } \\
\text { international trade (IR1) } \\
\text { - Strategic partnerships (IR2) } \\
\text { - Conforming to the calls of the } \\
\text { international space community to } \\
\text { introduce domestic space legislation } \\
\text { (IR3) }\end{array}$ \\
\hline
\end{tabular}

\section{ANALYSIS AND DISCUSSION}

'Within-case' analysis of the three countries of referencecase-study, India, Thailand and the Philippines, in terms of the key factors that have influenced their national space policies, followed by the 'cross-case' comparative analysis with Sri Lanka positioned as the central case study, was carried out following procedure that was comprehensively described under methodology section.

Within-case analysis mainly concentrated on the intrinsic policy drivers, and the relevant contextual factors, leading to identification of the directional and strategic elements of policy that they have influenced, in each of the three countries of reference-case-study. This analysis largely included insights into implicit elements of national space policies - as they manifestly find expression in the strategies, programmes and the institutional structures of the national space activities of respective countries - as well as what is currently available in the form of formally adopted and publicly declared policy.

Cross-case comparative analysis of the four case-studiespositioning Sri Lanka as the central case study and other three countries as reference-case-studies, in keeping with the methodological variant being advanced-was carried out based on the intrinsic policy drivers, contextual factors, and the elements of directional and strategic policy of the countries of reference-case-study, eventually leading to identification of policy imperatives for the directional and strategic elements of national space of Sri Lanka.

Since the objective of the present paper is to describe and establish the efficacy of a new methodological variant to an established approach of qualitative comparative policy analysis involving multiple case studies, wherein developing of a national space policy is being used only as a vehicle of explicating that innovative methodological variant, the full details of that substantive policy analysis are not warranted here. Therefore only a few selected points are discussed below to exemplify the analysis.

Therefore, only a few selected rows of the summarized table developed by the cross-case qualitative comparative analysis of the intrinsic policy drivers, are listed in the table 2 below, in order to exemplify the substantive details of the analysis.

Relevance of each intrinsic-policy driver, given in the above sample, as a substantive determinant of policy in respect of the central case study, Sri Lanka, as compared to respective reference case studies, is explicated below.

As for the group of intrinsic policy drivers identified under 'technological advancement', achievement of the status of a space capable country (intrinsic policy driver TA1) is relevant to Sri Lanka, as would be relevant to most countries, as a matter of national pride. The same applies to TA2 'enhanced capacity for technological innovation', which the national capacity in space technologies, as a core element of the advanced technological capabilities of a country, is generally known to directly strengthen.

Similarly, Sri Lanka, as well as Thailand and the Philippines, has no capability to develop a commercial space industry based on core-technological capabilities in space (intrinsic policy driver TA4), which is typically the domain of leading space faring countries such as India. Interestingly, development of intrinsically space enabled industries and 
services such as telecommunication services and direct-tohome satellite television (TA7) has no significant relevance to Sri Lanka, as compared to the other three countries, due to several special reasons. While, on the one hand, the country has little incentive to use satellites for domestic telecommunication or broadcasting, respectively due to its countrywide wireless broadband and optical fibre connectivity, and the efficient coverage of terrestrial broadcasting networks, on the other hand, it has little incentive to use satellites for external communication due to the country's far more efficient high speed submarine optical fibre connectivity with the rest of the world.

In the area of national security, while space based surveillance (NS2) is relevant to Sri Lanka, the country has only very limited scope for space assisted military operations (NS3).

Sustainable development represents an area of national interest where all six intrinsic policy drivers (SD1-6) have almost equal relevance across all four countries, regardless of their capabilities in space technologies, despite relatively low significance to Sri Lanka for connectivity.

Under the area of scientific advancement, Sri Lanka, along with Thailand and the Philippines, share only marginal capabilities on the prospects of creating new scientific knowledge in the area of space (SA1), which largely remains the domain of leading spacefaring nations.

\section{A. Policy Imperatives for Sri Lanka}

The eventual formulation of the directional and strategic policy elements that would potentially represent, and constitute, the policy imperatives in developing a national space policy for Sri Lanka were fundamentally informed by two aspects the above cross-case analysis, carried out positioning Sri Lanka as the central case study. The first is the relevance and significance of the intrinsic policy-drivers identified in respect of Sri Lanka, as exemplified in table 2 above. The second aspect is the cross-case comparison of those contextual factors that, in their own right, lead to certain elements of directional and strategic policy. For example, the elements of directional and strategic policy pertaining to such aspects as the institutional structure of the national space establishment, composition of various authorities, and their proximity to the power-centre of the government etc, are largely determined by the contextual factors related to the system of governance and public administration in Sri Lanka.

The directional and strategic policy elements that would potentially represent, and constitute, the policy imperatives in developing a national space policy for Sri Lanka, developed on the basis of the above analysis, are identified in the table 3 below

\section{CONCLUSION}

The research inquiry presented in the present paper endeavored to describe and establish 'qualitative comparative analysis with a central case study and multiple reference case studies' as an effective methodological variant of comparative policy analysis; while the methodological innovation being thus advanced is intended to be applied in the area of policy analysis that leads to policy development, the proposition was established for the specific public policy domain of national space policy in the present study.

The elements of directional and strategic policy identified in table 3 as policy imperatives that would constitute the national space policy of Sri Lanka, effectively constitute, and represent the character of, a well formulated national space

Table 2: Cross-Case Qualitative Comparative Analysis of Intrinsic Policy Drivers-A Representative Sample

\begin{tabular}{|c|c|c|c|c|c|}
\hline \multirow{3}{*}{$\begin{array}{l}\text { Area of national interest } \\
\text { with respect to space }\end{array}$} & \multirow{3}{*}{ Intrinsic policy driver } & \multicolumn{4}{|c|}{$\begin{array}{l}\text { Relevance of the intrinsic policy driver as a substantive determinant of } \\
\text { policy in respect of the respective reference case studies and the central } \\
\text { case study in the present context }\end{array}$} \\
\hline & & \multicolumn{3}{|c|}{ Reference case study } & $\begin{array}{c}\text { Central case } \\
\text { study }\end{array}$ \\
\hline & & India & Thailand & Philippines & Sri Lanka \\
\hline \multirow{4}{*}{$\begin{array}{c}\text { Technological } \\
\text { Advancement (TA) }\end{array}$} & $\begin{array}{l}\text { National pride: achievement of the status } \\
\text { of a space-capable or space-faring nation } \\
\text { (TA1) }\end{array}$ & $\begin{array}{l}\text { Relevant. Achieve } \\
\text { a leadership } \\
\text { position among } \\
\text { spacefaring } \\
\text { nations }\end{array}$ & $\begin{array}{c}\text { Relevant. } \\
\text { Achieve a } \\
\text { leadership } \\
\text { position among } \\
\text { emerging space } \\
\text { nations } \\
\end{array}$ & $\begin{array}{l}\text { Relevant. } \\
\text { Achieve } \\
\text { recognition as } \\
\text { an emerging } \\
\text { space nation }\end{array}$ & $\begin{array}{l}\text { Relevant. } \\
\text { Achieve } \\
\text { recognition as } \\
\text { an emerging } \\
\text { space nation }\end{array}$ \\
\hline & $\begin{array}{l}\text { Enhanced national capacity for } \\
\text { technological innovation (TA2) }\end{array}$ & Relevant & Relevant & Relevant & Relevant \\
\hline & $\begin{array}{l}\text { Development of commercial space } \\
\text { industry based on core technology } \\
\text { capabilities and services [eg. } \\
\text { manufacturing advanced spacecraft and } \\
\text { launch vehicles, and operating launch } \\
\text { services] (TA4) }\end{array}$ & $\begin{array}{l}\text { Relevant and fully } \\
\text { capable }\end{array}$ & $\begin{array}{l}\text { No significant } \\
\text { capability }\end{array}$ & No capability & No capability \\
\hline & $\begin{array}{l}\text { Development of intrinsically space- } \\
\text { enabled industries and services [eg. } \\
\text { telecommunication services } \\
\text { and direct-to-home satellite television] } \\
\text { (TA7) }\end{array}$ & Relevant & Relevant & Relevant & $\begin{array}{l}\text { Not } \\
\text { significantly } \\
\text { relevant }\end{array}$ \\
\hline
\end{tabular}




\begin{tabular}{|c|c|c|c|c|c|}
\hline National Security (NS) & Space based Surveillance (NS2) & Relevant & Relevant & Relevant & Relevant \\
\cline { 2 - 6 } & $\begin{array}{c}\text { Space technology assisted military } \\
\text { operations (NS3) }\end{array}$ & Relevant & $\begin{array}{c}\text { Marginally } \\
\text { relevant }\end{array}$ & $\begin{array}{c}\text { Marginally } \\
\text { relevant }\end{array}$ & $\begin{array}{c}\text { Marginally } \\
\text { relevant }\end{array}$ \\
\hline \multirow{4}{*}{$\begin{array}{c}\text { Sustainable } \\
\text { Development (SD) }\end{array}$} & $\begin{array}{c}\text { Space applications for disaster risk } \\
\text { reduction and resilience (SD1) }\end{array}$ & Relevant & Relevant & Relevant & Relevant \\
\cline { 2 - 6 } & $\begin{array}{c}\text { Space applications for natural resources } \\
\text { management (SD2) }\end{array}$ & Relevant & Relevant & Relevant & Relevant \\
\cline { 2 - 6 } (SD3) & $\begin{array}{c}\text { Space applications forial development } \\
\text { Space applications for climate change } \\
\text { mitigation (SD4) }\end{array}$ & Relevant & Relevant & Relevant & Relevant \\
\cline { 2 - 6 } & Space applications for connectivity (SD5) & Relevant & Relevant & Relevant & Relevant \\
\cline { 2 - 6 } & $\begin{array}{c}\text { Space applications for clean and modern } \\
\text { energy (SD6) }\end{array}$ & Relevant & Relevant & Relevant \\
Relevant
\end{tabular}

Table 3: Policy Imperatives for Sri Lanka

\begin{tabular}{|c|c|}
\hline Direct & Strategic Policy Elements \\
\hline 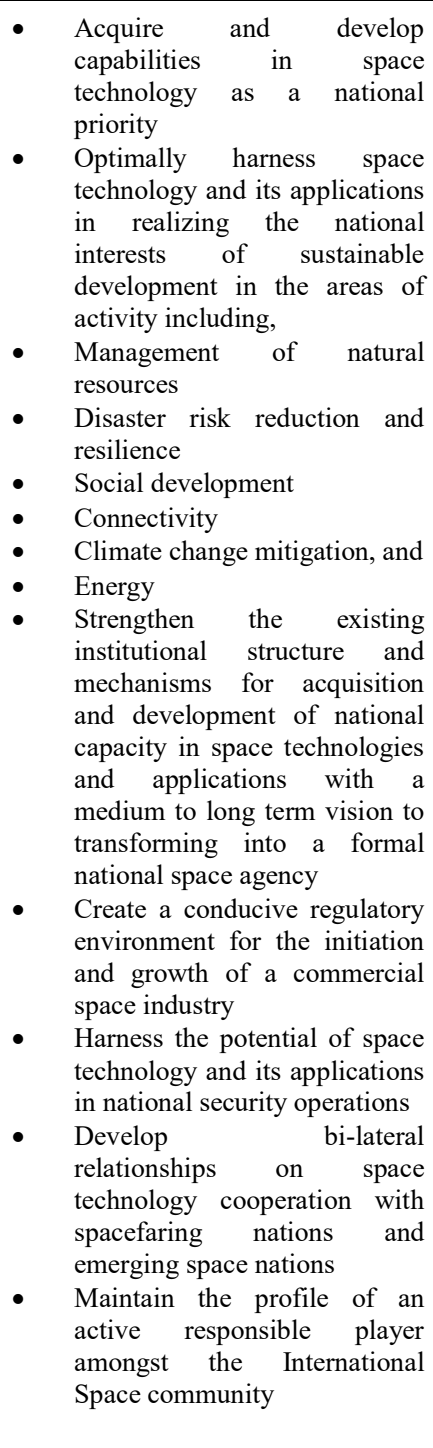 & 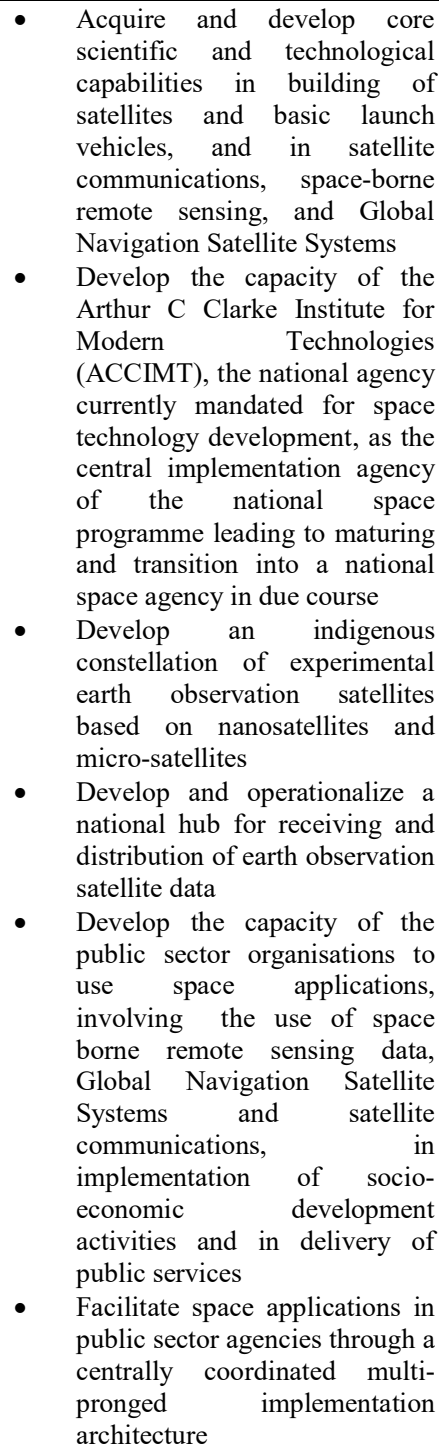 \\
\hline
\end{tabular}

- $\quad$ Strengthen applications in the priority areas including land use and land cover mapping, agricultural crops monitoring, water resources information systems; forest conservation plans, biodiversity and coral mapping; ocean state forecasts; rural development; urban planning and development; monitoring of water bodies; and disaster management support including mapping and monitoring of cyclones, floods, landslides, monitoring of agricultural drought, forest fire, earthquakes, and monitoring and forecast of extreme weather events

- Develop the capacity of national agencies responsible for national security and defence to harness the potential of space technologies and applications

- Establish a national space commission to promote, develop and regulate national space activities with the representation of topmost officials of the relevant national agencies that carry the responsibility for the subjects of science and technology, natural resource management, vocational and higher education, telecommunication, agriculture, national security, environment, weather, urban development, and transport.

- Conduct training programmes through ACCIMT, national universities and other institutes of advanced professional training, to develop the critical mass of human resources necessary for effective harnessing of the potential of space technologies and applications by the country 
- $\quad$ Foster the development of a private sector driven commercial space industry targeting the upstream and downstream activities of the technology and infrastructure development supply chain

- $\quad$ Conduct collaborative projects on technology development and applications through multiple bi-lateral relationships on space technology cooperation with spacefaring nations and emerging space nations

- Maintain an active presence at various fora of the international space community, including the relevant United Nations forums.

Policy that could effectively guide the acquisition and development of national capacity in space technologies and their applications, and regulation of national space activities, of Sri Lanka. Those policy imperatives, when viewed in relation to their context, resemble on the one hand those comparable elements of directional and strategic policy of the largely implicit space policies of India and Thailand, while on the other hand resembling the comparable elements directional and strategic policy of the publicly declared national space policy of the Philippines.

This is certainly testimony to the efficacy of the methodological innovation that was intended to establish in the present inquiry. It has to be specifically stated that such comparison remains perfectly legitimate in methodological terms, despite the fact that those reference-case-studies did inform the cross-case comparative analysis leading to identification of those policy imperatives. That methodological legitimacy is premised on the fundamentally inductive, interpretative character of the approach of inquiry that was followed throughout this qualitative research study, as opposed to a fundamentally deductive approach that would limit such comparison.

The present study, in addition to achieving its main objective of describing and establishing 'qualitative comparative analysis with a central case study and multiple reference case studies' as an effective methodological variant of comparative policy analysis in developing a national space policy, also provides an effective methodological framework for developing the national space policies of developing countries - a contemporary need of many a developing country making its entry into the space domain.

Finally, it provides an innovative variant to the general theoretical framework of 'qualitative comparative analysis amongst multiple case studies', the use of which may be extended to policy analysis involving the development of public policy in many a distinctly identifiable specific area of public policy in developing countries, where they stand to benefit from the experience of other countries, in the relevant domain, through comparative policy analysis.

\section{REFERENCES}

[1] Majchrzak, A., 2011. Methods For Policy Research. Thousand Oaks: SAGE Publications, Inc., p.2.

[2] Betterthesis.dk. 2021. Lesson 4: Policy Research|Better Thesis. [online] Available at: <http://betterthesis.dk/researchmethods/lesson-3-policy-research $>$ [Accessed 24 January 2021].

[3] Porta, D. della (2008) "Comparative analysis: case-oriented versus variable-oriented research," in Della Porta, D. and Keating, M. (eds) Approaches and Methodologies in the Social Sciences: A Pluralist Perspective. Cambridge: Cambridge University Press, pp. 198-222. doi: 10.1017/CBO9780511801938.012.

[4] Collier, D., 2021. The Comparative Method. [online] Poseidon01.ssrn.com. Available at: $<$ https://poseidon01.ssrn.com/delivery.php?ID $=69008311602712$ 50940770950950970071260140800370070540600880981171050 90004071002122005030030106023013098105087000112085092 10510010604504705209307507811211912612508800800807907 91100240100280701110041200200941260121210011090910110 $70029099001127100099075002 \&$ EXT $=$ pdf\&INDEX $=$ TRUE $>$ [Accessed 24 January 2021].

[5] Berg-Schlosser, D., De Meur, G., Rihoux, B. and Ragin, C., 2012. Qualitative Comparative Analysis (QCA) As An Approach - SAGE Research Methods. [online] Methods.sagepub.com. Available at: $<\mathrm{https}$ ://methods.sagepub.com/book/configurational-comparativemethods/n1.xml $>$ [Accessed 24 January 2021].

[6] Agranoff, R. \& Radin, Beryl. (1991). The comparative case study approach in public administration. Research in Public Administration. 1. 203-231.

[7] Creswell, J., 2013. Qualitative Inquiry And Research Design. London: Sage Publications.

[8] Isro.gov.in. 1997. A Policy Framework For Satellite Communication In India. [online] Available at: $<$ https://www.isro.gov.in/sites/default/files/article-files/indiasspace-policy-0/satcom-policy.pdf $>$ [Accessed 24 January 2021].

[9] Isro.gov.in. 2011. Remote Sensing Data Policy - 2011. [online] Available at: <https://www.isro.gov.in/indias-space-policy0\#: : text $=$ To $\% 20$ cater $\% 20$ to $\% 20$ the $\% 20$ developmental,from $\% 20$ Indian\%20and\%20foreign\%20satellites.> [Accessed 24 January 2021].

[10] Geo-Informatics and Space Technology Development Agency: GISTDA Thailand, 2019. Thailand National Space Master Plan (2017 - 2036). [online] Unoosa.org. Available at: $<$ https://www.unoosa.org/documents/pdf/spacelaw/activities/2019 /T5-3-

PC_Leveraging_Space_Law_Capability_for_new_space_actors_i n_Asia_Pacific_Region.pdf $>$ [Accessed 24 January 2021].Officialgazette.gov.ph. 2019. Philippine Space Act Republic Act No 11363. [online] Available at: $<$ https://www.officialgazette.gov.ph/downloads/2019/08aug/2019 0808-RA-11363-RRD.pdf $>$ [Accessed 24 January 2021]. 